\title{
Influence of metal working fluid on chip formation and mechanical loads in orthogonal cutting
}

\author{
Berend Denkena ${ }^{1} \cdot$ Alexander Krödel $^{1} \cdot$ Lars Ellersiek $^{1}$ (D)
}

Received: 31 July 2021 / Accepted: 29 September 2021 / Published online: 8 October 2021

(c) The Author(s) 2021, corrected publication 2022

\begin{abstract}
Metal working fluids are used in machining processes of many hard-to-cut materials to increase tool life and productivity. Thereby, the metal working fluids act on the thermal and on the mechanical loads of the tool. The changing mechanical loads can mostly be attributed to the changing friction between rake face and chip and changes in the chip formation, e.g., the contact length between rake face and chip. However, analyzing those effects is challenging, since a detailed look at the chip formation process is prevented by the metal working fluid. In this paper, a novel planing test rig is presented, which enables high-speed recordings of the machining process and process force measurements while using metal working fluids. Experiments reveal that process forces are reduced with increasing pressure of the metal working fluid. However, the average friction coefficient only changes slightly, which indicates that the reduced process forces are mainly the result of reduced contact lengths between rake face and chip.
\end{abstract}

Keywords Metal working fluid · Chip formation $\cdot$ Friction $\cdot$ Lubrication

\section{Introduction}

The use of metal working fluids (MWF) is an important approach to reduce tool wear and increase productivity in machining processes. The positive effect of MWF is known for a long time, and thus, MWF is commonly used especially for hard-to-cut materials. Current investigations mostly focus on the use of high-pressure cooling strategies. An increased tool-life due to high-pressure machining strategies could be shown for machining of titanium [1, 2], Inconel 718 [3, 4], and steel [5].

The main functions of MWF are cooling and lubrication. Temperature reductions in wet machining processes compared to dry processes were presented by various authors and can be attributed to several effects, e.g., reduced friction and heat absorption of the MWF $[2,6]$. The influence of MWF on friction is often investigated on tribometers. Claudin et al. used an open pin-cylinder tribometer, in which the pin (cemented carbide with TiN coating) moves helical

Lars Ellersiek

ellersiek@ifw.uni-hannover.de

1 Institute of Production Engineering and Machine Tools (IFW), Leibniz Universität Hannover, An der Universität 2, 30823 Garbsen, Germany along the circumferential side of the cylinder (AISI4140) [7]. The investigations showed a reduction of the friction coefficient from $\mu=0.5$ to $\mu=0.15$ when using oil for low sliding velocities $v_{s}=10 \mathrm{~m} / \mathrm{min}$. For high sliding velocities $v_{s}=300 \mathrm{~m} / \mathrm{min}$, low friction coefficients of $\mu=0.1-0.2$ were measured in dry and wet experiments. These results were later validated for different oil types [8] and were also confirmed in [9] with an uncoated pin. Lakner and Hardt used a defined contact between the flank face of a TiCN-coated cemented carbide tool and an AISI4140 shaft to identify the friction coefficient [10]. They determined friction coefficients $\mu=0.2-0.3$ for dry and wet processes and sliding velocities $\mathrm{v}_{\mathrm{s}}=40-120 \mathrm{~m} / \mathrm{min}$.

All tribometer tests have in common that the local varying boundary conditions (normal loads, process temperatures, sliding velocities) differ from the real cutting process. Thus, deviations compared to the friction in actual cutting processes can occur.

Although a large number of publications deal with the advantages of MWF, investigations on the influence of MWF on local loads and chip formation are very limited due to the limited visibility of the cutting process when using MWF. Many researchers found improved chip breakage and an increased chip curl, which also indicates reduced contact lengths $[5,11]$. In regard to reduced tangential stresses on 
the rake face due to the lubrication of MWF, Childs [12] and Williams and Tabor [13] stated that the penetration depth of the MWF in contact area between chip and rake face is very low. However, the penetration depth might be increased by increasing the roughness of the rake face [12].

In summary, there is a lack of investigations concerning the influence of the MWF on chip formation, e.g., contact lengths and plowing forces resulting from the minimum chip thickness $\mathrm{h}_{\min }$. A detailed analysis of the chip formation process and process forces, however, could enable quantitative and qualitative statements about mechanical stresses on the cutting wedge [14]. Thereby, more detailed knowledge about the influence of MWF on friction phenomena in cutting processes could be generated.

In this paper, a novel test setup is introduced, which allows high-speed recordings of the chip formation process on a planing test rig during wet machining. The MWF is brought to the tool rake face with high-pressure by a selfdeveloped accumulator system. Using a high-speed camera and a three-component dynamometer, statements can be made about the chip formation process and mechanical loads during chip formation.

\section{Experimental procedure and methodology}

\subsection{Planing test rig}

For the investigations, a planing test rig previously used for dry cutting experiments $[14,15]$ was extended to perform experiments with MWF. To achieve high dynamic MWF pressures without long response times, an accumulator systems is used (Fig. 1). An accumulator Hydac SBO100-2E1/112U-100AK with a volume of $2 \mathrm{~L}$ and a maximum pressure of 100 bar was used. The accumulator will be charged with a hand pump Binda PT70 with a maximum pressure of $p=70 \mathrm{bar}$. Since the accumulator is pre-charged with nitrogen, the MWF can be stored in the accumulator with defined pressures. By opening the valve block of the accumulator (Hydac SAF10E12Z1T100A), the MWF is flowing towards the nozzle (diameter $1 \mathrm{~mm}$, $A_{\text {nozzle }}=0.79 \mathrm{~mm}^{2}$ ) and is then applied to the rake face of the cutting tool. The valve is controlled by a USB relay card, which allows an automated valve control. Thus, the control can also be coupled with the movement of the planing test rig.

The tool is stationary and cuts the workpiece mounted on the table, which is driven by a linear direct drive. Thus, an orthogonal cut is realized, whereby the movement of the table equals the cutting speed. With the setup, a maximum cutting speed of $500 \mathrm{~m} / \mathrm{min}$ can be realized. To protect the test rig from the MWF, a housing was built on the table.

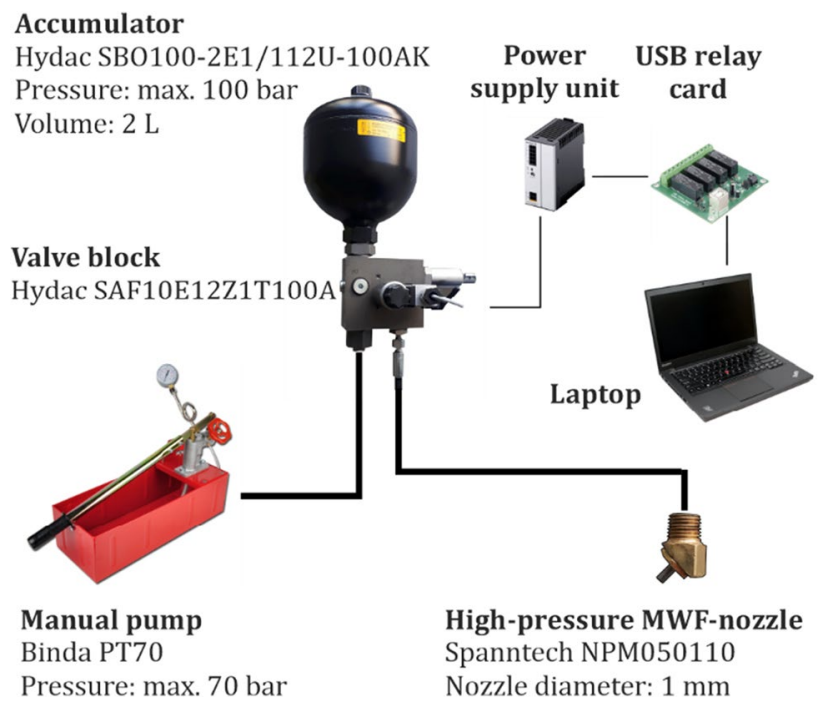

Fig. 1 Setup of the accumulator system

The housing has a recess in the area of the workpiece. By inserting a sapphire glass plate between workpiece and housing, high-speed recordings of the chip formation process can be achieved (Fig. 2). Additionally, the sapphire glass plate limits the material side flow. Besides the housing, the holder of the nozzle protects the high-speed camera against MWF. To have a view on nozzle and tool holder, an adapted nozzle holder is used in Fig. 2 without a protection wall for the high-speed camera. The contour of the complete nozzle holder, which protects the high-speed camera against the MWF, is schematically plotted. The bottom picture in Fig. 2 shows the point of view of the high-speed camera. The nozzle outlet is tilted by $\lambda=40^{\circ}$ with respect to the rake face. In future investigations, additional experiments with tilt angle of $0^{\circ}$ are planned.

\subsection{Tools, material and metal working fluid}

Two tools of type SNMA120408 were used in the current investigations. The tools differ in the roughness of the rake face (Fig. 3). One tool was not further prepared on the rake face and shows typical grinding grooves nearly perpendicular to the cutting edge (Fig. 3a). The other tool was polished on the rake face, which leads to a reduced roughness (Fig. 3b). The clearance angle of the tools was reduced by grinding. With the chosen tool holder, a clearance angle $\alpha=14^{\circ}$ and a rake angle $\gamma=1^{\circ}$ were applied. The cutting edge rounding was prepared by brushing. A symmetric cutting-edge rounding of $\bar{S}=35 \mu \mathrm{m}$ was chosen, which is common for machining of steel [16]. After the tool preparation, the tool was coated with a PVD-TiAlN coating (thickness $2 \mu \mathrm{m})$. 


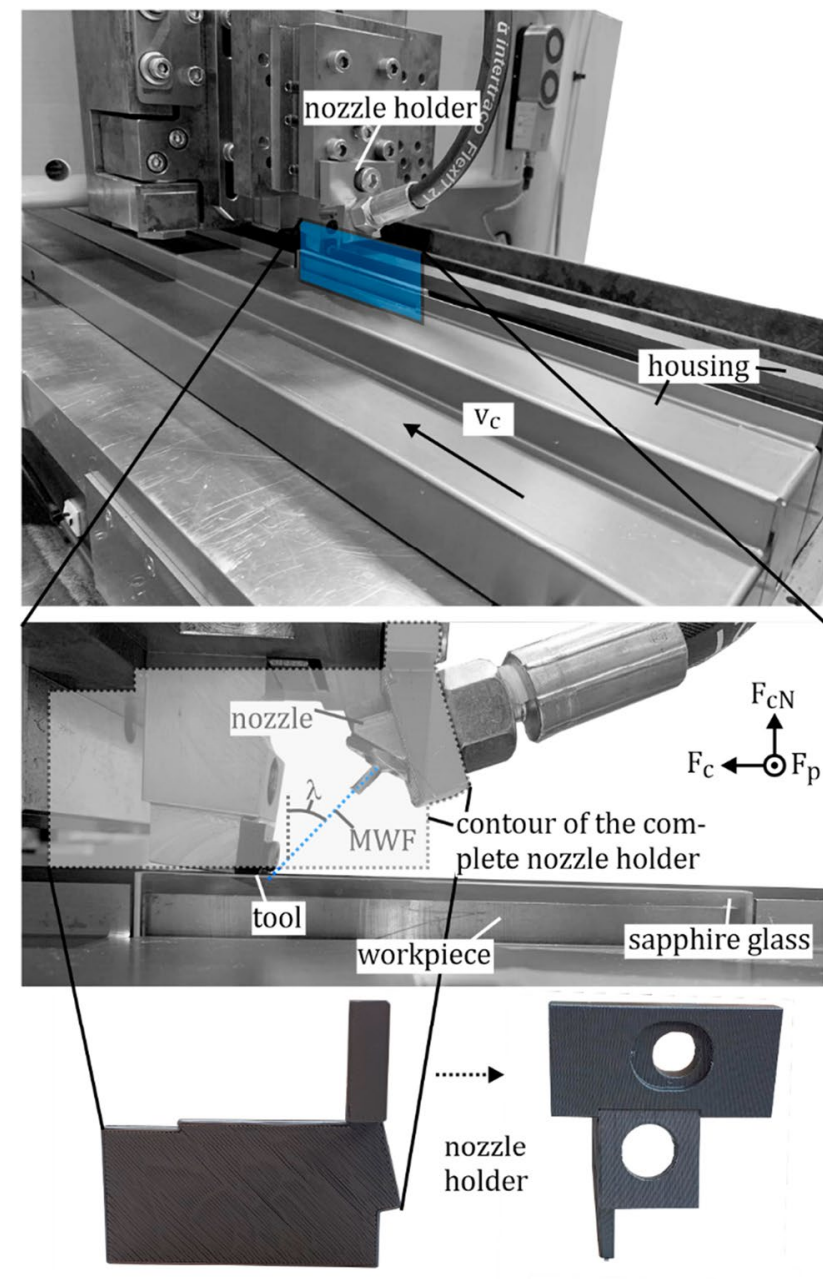

Fig. 2 Setup of the planing test rig

Quenched and tempered AISI4140 was used as workpiece material. A Vickers hardness of 411 HV1 and a Young modulus $E=203.5 \mathrm{GPa}$ were measured at room temperature with a TriboIndenter TI950. Additionally, a heating stage xSol800 was used to measure the Young modulus for higher temperatures. $E=183.6 \mathrm{GPa}$ was measured at $300^{\circ} \mathrm{C}$ and $E=167.4 \mathrm{GPa}$ was measured at $400{ }^{\circ} \mathrm{C}$. The cutting length of the process is $53.3 \mathrm{~mm}$. The undeformed chip thickness increases on the first $33.3 \mathrm{~mm}$ of the process from 0 to $0.1 \mathrm{~mm}$ and is the kept constant for $20 \mathrm{~mm}$. All investigations were conducted with a width of cut $b=2 \mathrm{~mm}$ and a cutting speed $\mathrm{v}_{\mathrm{c}}=120 \mathrm{~m} / \mathrm{min}$.

Ester-based oil Blaser Vascomill CSF35 was used as MWF. The oil has a viscosity of $35 \mathrm{~mm}^{2} / \mathrm{s}\left(T=40^{\circ} \mathrm{C}\right)$, a density $\rho=0.9 \mathrm{~g} / \mathrm{cm}^{3}$, and a flash point of $350{ }^{\circ} \mathrm{C}$. For the investigations, MWF pressures of $p=10$ bar and $p=30$ bar were used. This equals a flow rate $\mathrm{Q}=2.2 \mathrm{~L} / \mathrm{min}$ and $\mathrm{Q}=3.8 \mathrm{~L} /$ $\mathrm{min}$. The accumulator was pre-charged with nitrogen pressure of $p_{0}=3$ bar and $p_{0}=8 \mathrm{bar}$, respectively, to reach the

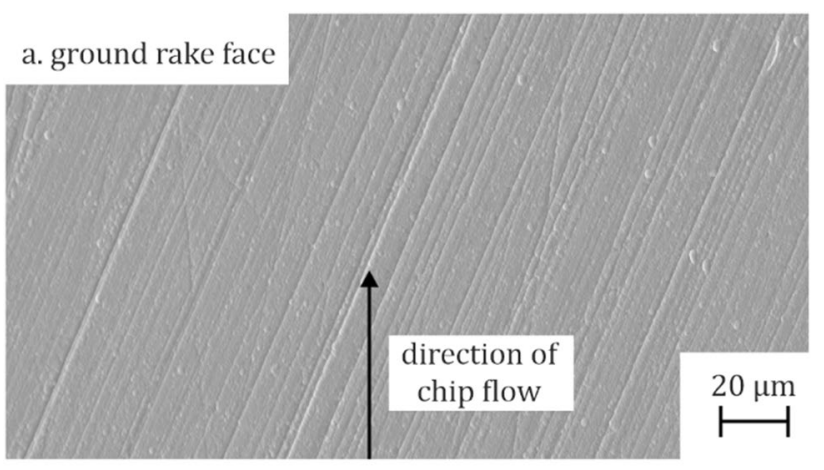

b. polished rake face

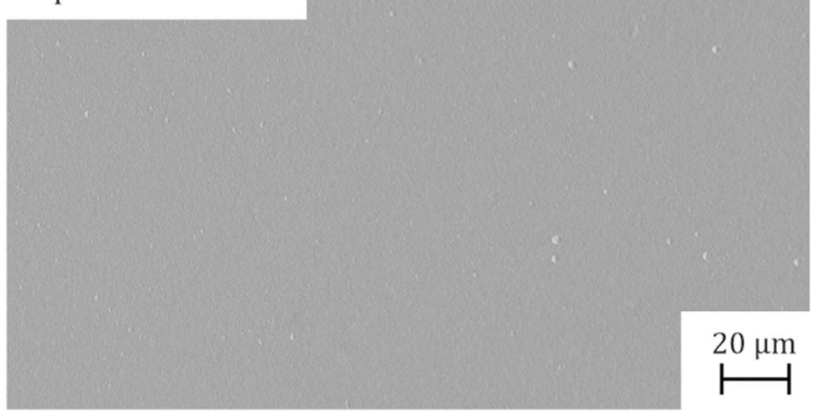

Fig. 3 Surface of the used rake faces: a ground rake face, $b$ polished rake face

required maximum MWF pressure. Approximately $1.4 \mathrm{~L}$ of MWF was stored in the accumulator. It has to be mentioned that the pressure reduces during the cutting process due to the loss of MWF volume. However, because of the short process time, the pressure losses are low. The valve of the accumulator is opened parallel to the beginning of the movement of the planing table. The workpiece reaches the tool after approximately $300 \mathrm{~ms}$. The cutting process itself lasts $27 \mathrm{~ms}$. By assuming a constant flow rate over these $327 \mathrm{~ms}$, the volume of the MWF in the accumulator only reduces by $13 \mathrm{~mL}$ for processes with $p=10$ bar and $22 \mathrm{~mL}$ for processes with $p=30$ bar, leading to pressure losses lower than $5 \%$.

The two tools with different rake face roughness are used in dry cutting, wet cutting with pressure $p=10 \mathrm{bar}$, and wet cutting with $p=30$ bar. Every process was repeated once. Thus, 12 planing tests were carried out.

\subsection{Analytical methods}

A high-speed camera Photron Fastcam SA5 is used to record high-speed images. A framerate of 20,000 fps, a shutter of $1 / 106,000 \mathrm{~s}$, and a $6 \times$ magnification were used. SMETec LED-P40 was used as light source.

Process forces were measured in cutting and cutting normal direction using a Kistler Dynamometer Type 9257B with a sampling rate of 44,100 Hz. A typical force measurement is shown in Fig. 4. The first increase of a 


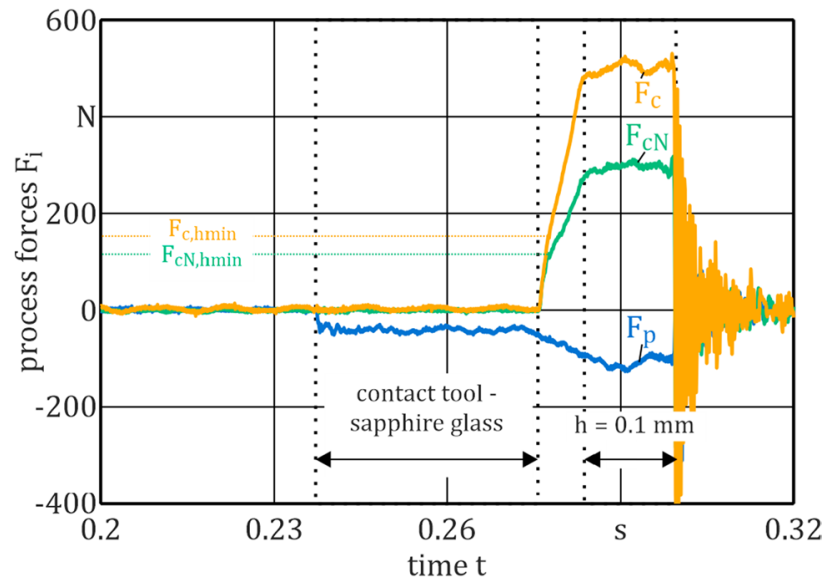

Fig. 4 Force curve of a cutting process with ground rake face and pressure $p=10$ bar

process force can be observed for the passive force $F_{p}$, when the tool gets in contact with the sapphire glass. No significant force increase can be observed for cutting force $\mathrm{F}_{\mathrm{c}}$ and cutting normal force $\mathrm{F}_{\mathrm{cN}}$. This is also evident for dry cutting processes. Thus, it can be concluded that the contact between sapphire glass and tool does not influence $\mathrm{F}_{\mathrm{c}}$ and $\mathrm{F}_{\mathrm{cN}}$ due to the low friction between sapphire glass and cutting tool and the low passive forces. After approximately $0.27 \mathrm{~s}$, the tool gets in contact with the workpiece. The first contact between tool and workpiece is characterized by plowing effects underneath the cutting edge rounding and no chip formation occurs. After the minimum chip thickness, $h_{\min }$ is exceeded, the chip formation begins. A constant increase of the process forces can be observed until a constant uncut chip thickness of $h=0.1 \mathrm{~mm}$ is reached. The time of the cutting process with constant uncut chip thickness $h$ is used for the analysis of process forces, contact lengths, and friction coefficients.

Furthermore, even though the free oil jet gets in contact with the cutting tool directly in the beginning of the movement of the test rig $(t=0)$, no significant influence of the free jet on the process forces can be observed. The propulsive force of the free jet can be calculated with

$F_{\text {jet }}(p)=\rho \bullet v_{\text {jet }}^{2} \bullet A_{\text {nozzle }}$

and

$v_{j e t}=\sqrt{\frac{2 p}{\rho}}$

This results in propulsive jet forces of $F_{\text {jet }}$ $(10 \mathrm{bar})=1.6 \mathrm{~N}$ and $\mathrm{F}_{\text {jet }}(30 \mathrm{bar})=4.7 \mathrm{~N}$, which is less than $1 \%$ of the measured cutting forces. The force of the free jet can therefore be neglected, when analyzing the mechanical loads of the cutting process.

\section{Results and discussion}

\subsection{Chip formation}

The chip formation is analyzed using high-speed recordings. Some exemplary high-speed images of the dry machining process, the wet machining process with $p=10$ bar and the wet machining process with $p=30$ bar are given in Fig. 5 .

Tools with ground rake face are pictured in the images. However, similar effects are also observed for the tools with polished rake face. During the entry of the tool, the undeformed chip thickness continuously increases. The chip of the dry cutting process exhibits a strong chip curl during the initial chip formation (Fig. 5b). For a stationary process with constant undeformed chip thickness $h=0.1 \mathrm{~mm}$, the chip formation of the dry cutting process is characterized by a high contact length $\mathrm{cl}=0.56 \mathrm{~mm}$ (Fig. $5 \mathrm{c}$ ). Before the chip formation of the wet cutting processes begins, the MWF stream and a MWF film on rake face and workpiece surface are visible (Fig. $5 \mathrm{~d}, \mathrm{~g}$ ). The initial chip formation of the wet cutting process with $p=10$ bar is characterized by a reduced chip curl compared to the dry process (Fig. 5e). This can be attributed to reduced temperatures in the chip-rake face contact area, which leads to reduced thermal-induced stresses in the chip. During the stationary chip formation, the contact length $\mathrm{cl}$ is reduced compared to the dry process (Fig. 5f) due to the mechanical forces of the MWF acting on the chip. For wet processes with $p=30 \mathrm{bar}$, the chip is pressed against the rake face during initial chip formation (Fig. 5h). However, when a certain chip length is exceeded, the mechanical forces of the MWF press the chip against the workpiece surface, and the contact length is lower compared to the dry process and the wet process with $p=10$ bar (Fig. 5i).

A detailed view on the measured contact lengths for the individual processes is given in Fig. 6. The highest contact lengths result from the dry cutting processes with mean values of $\mathrm{cl}=0.52 \mathrm{~mm}$ (ground rake face) and $\mathrm{cl}=0.58 \mathrm{~mm}$ (polished rake face). With MWF pressure $p=10 \mathrm{bar}$, the contact length strongly decreases. A further decrease of the contact length can be observed with increasing pressure. The lowest contact lengths exist for wet process ( $p=30 \mathrm{bar}$ ) and tools with a ground rake face with a mean value $\mathrm{cl}=0.22 \mathrm{~mm}$. This can be attributed to higher MWF velocity and the higher MWF volume, which leads to higher forces acting on the surface of the chip. Overall, a reduction of the mean contact length from the dry process to the wet process with $p=30$ bar from 58\% for the ground rake face and $49 \%$ for the polished rake face was measured. Regarding the rake face conditions, slightly 

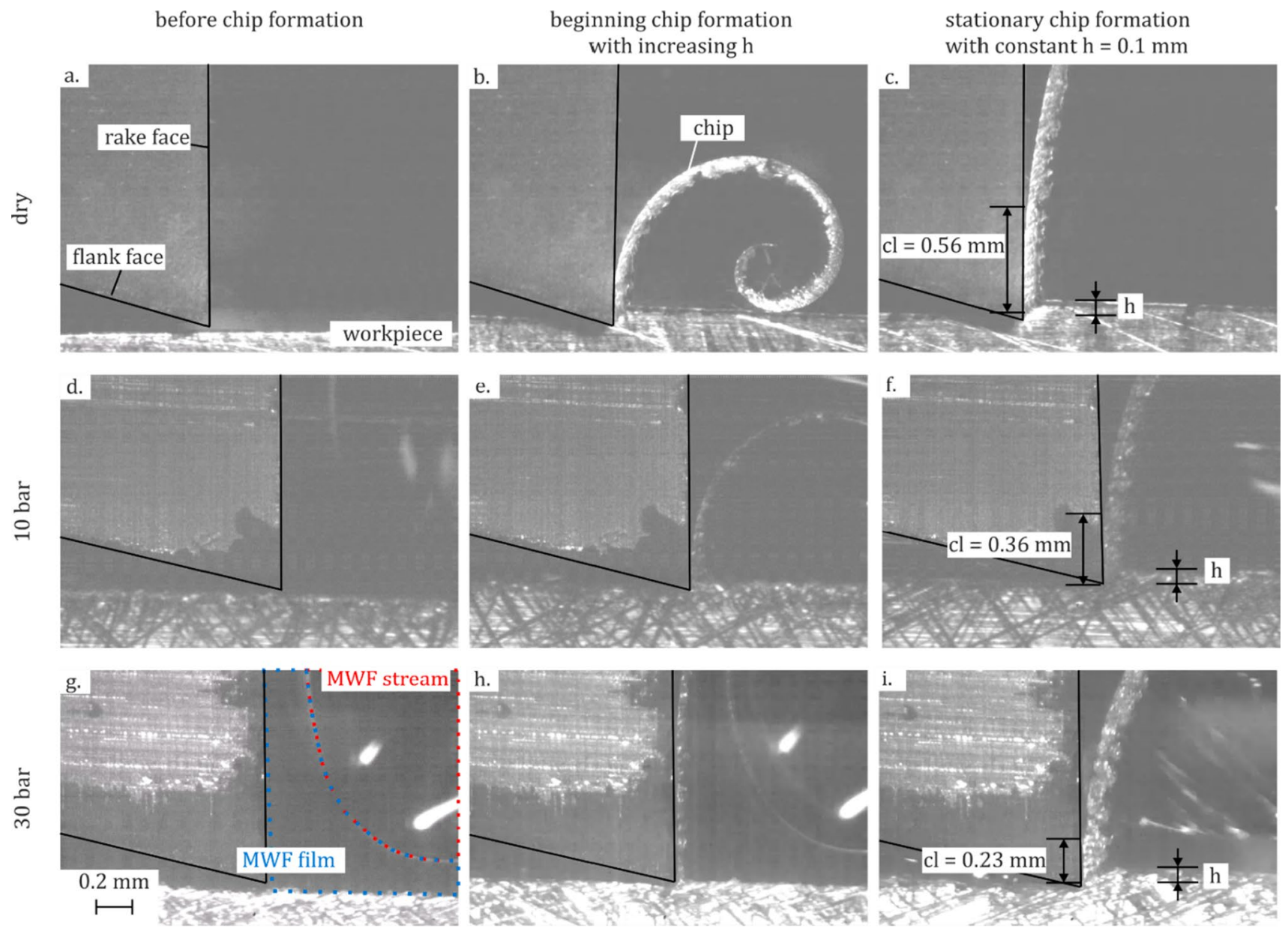

Fig. 5 Chip formation process for different stages of chip formation with tools with ground rake face for a dry cutting process (a-c), a wet process with $p=10$ bar $(\mathrm{d}-\mathrm{f})$, and a wet process with $p=30$ bar $(\mathrm{g}-\mathrm{i})$

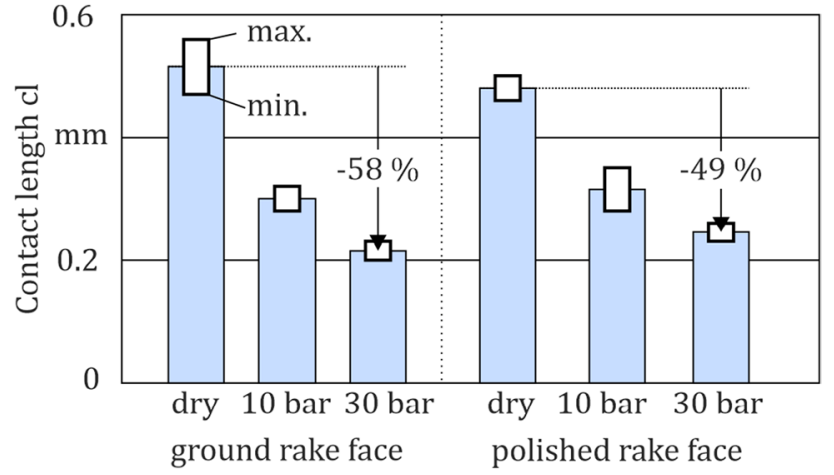

Fig. 6 Measured contact lengths for the individual processes

higher contact lengths were measured for the ground rake face during dry cutting processes and for the polished rake faces during wet cutting processes. However, the differences are in the range of the error bars and are therefore of low significance.
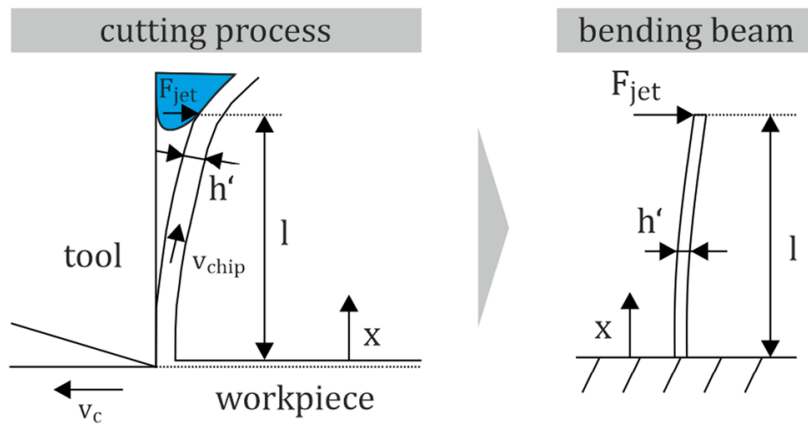

Fig. 7 Model of the chip formation process as bending beam

The distinctive reduction of the contact lengths is in contrast to the low jet forces of $1.6 \mathrm{~N}$ (10 bar) and $4.7 \mathrm{~N}$ (30 bar). To analyze this effect in more detail, the chip is modeled as a bending beam (Fig. 7). The chip formation process can be transferred into a bending beam, by assuming that the jet force $F_{\text {jet }}$ is acting on a defined distance 1 to the 
primary shear zone. The chip curvature is neglected in the model. The additional deflection of the chip due to the jet force $\mathrm{F}_{\text {jet }}$ can then be calculated with

$w(x)=\frac{F_{j e t} \cdot l \cdot x^{2}}{6 \cdot E \cdot I}\left(3-\frac{x}{l}\right)$

and

$I=\frac{b \cdot h^{\prime 3}}{12}$

Based on the dimensions of the final chip (see Fig. 8), it is assumed that the jet force of the MWF acts in a distance $1=3 \mathrm{~mm}$. The chip thickness was determined in the high speed videos with $h^{\prime}=160 \mu \mathrm{m}$ and the chip width is predefined with $b=2 \mathrm{~mm}$. Moreover, a Young modulus of 203.5 $\mathrm{GPa}$ is assumed. With those values, an additional deflection of the chip at $x=3 \mathrm{~mm}$ of $w=103.5 \mu \mathrm{m}\left(\mathrm{F}_{\text {jet }}=1.6 \mathrm{~N}\right)$ and $w=304.5 \mu \mathrm{m}\left(\mathrm{F}_{\text {jet }}=4.7 \mathrm{~N}\right)$ can be calculated. Thus, even though the jet forces are low compared to the cutting forces, a significant deflection can be achieved. This can be attributed to the characteristic form of the chip, especially the low chip thickness h', which favors elastic deformations. In addition, the distance to the primary shear zone 1 acts as a lever and increases the bending ability of the chip.

The influence of MWF on chip formation is also visible when looking at the chips after the process (Fig. 8). While characteristic blue annealing colors appear on the chips machined without MWF, the chips from the wet processes have the same silver-metallic color as the workpiece. This proves the occurrence of lower temperatures during wet machining. Blue annealing colors on steel are typical for temperatures over $250{ }^{\circ} \mathrm{C}$, while the silver-metallic color indicates temperatures below $200{ }^{\circ} \mathrm{C}$ [17].

In addition to the visual inspection of the chips, the chips were cleaned and the chemical composition on the chip surface, which was in direct contact with the rake face, was

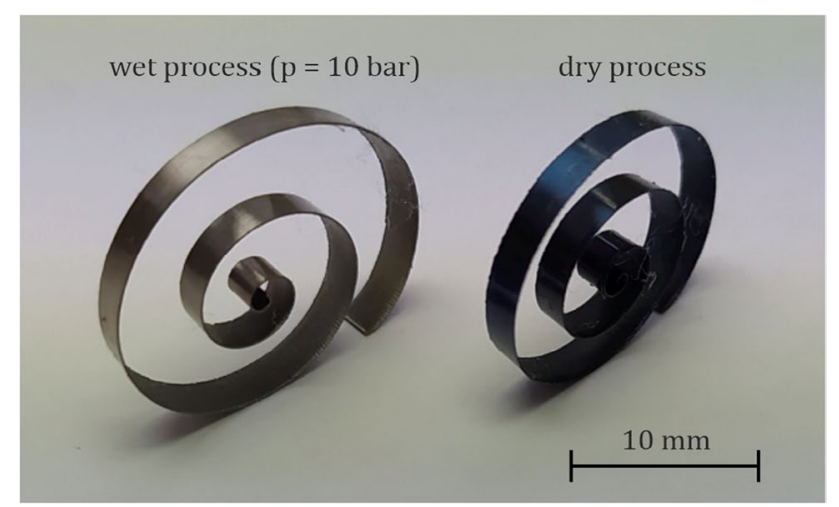

Fig. 8 Chips of wet ( $p=10$ bar) and dry cutting processes (ground rake face) measured using EDX. No significant changes in the chemical composition were found for the chips of the wet process, indicating no chemical reactions between chip and MWF. In contrast, an oxygen content of $6.59 \mathrm{wt} \%$ were measured on the chips of the dry process, indicating the formation of iron oxide and higher temperatures in the dry machining process.

\subsection{Mechanical loads}

The measured process forces in cutting and cutting normal direction are shown in Fig. 9. Measurement deviations of up to $109 \mathrm{~N}$ were identified. A possible source of error might be inaccuracies of the set undeformed chip thickness. This is also indicated by the fact that higher deviations of the process forces correlate with higher deviations of the contact lengths. Process forces as well as contact lengths increase with increasing undeformed chip thickness as stated in [14].

Similar trends for changes in the process forces can be seen for cutting and cutting normal forces. However, the measured forces and force differences for the individual processes are lower for the cutting normal force. The highest forces occur for dry processes with polished rake face with a mean value of $F_{c}=633 \mathrm{~N}$ and $F_{c N}=354 \mathrm{~N}$. By using MWF with pressure $p=10 \mathrm{bar}$, the process forces decrease regardless of the rake face condition. A changing lubrication on the rake face would only influence the cutting normal force $\mathrm{F}_{\mathrm{cN}}$ significantly, since $\mathrm{F}_{\mathrm{cN}}$ approximately acts tangential to the rake face. However, as pictured in Fig. 9, $\mathrm{F}_{\mathrm{cN}}$ as well as $\mathrm{F}_{\mathrm{c}}$ decrease when using MWF. Thus, the main reason for decreasing process forces is likely to be the decreasing contact length. By increasing the MWF pressure to $p=30 \mathrm{bar}$, a further reduction of the process forces is visible. This is in line with a decrease of the contact length. Concerning the rake face condition, slightly lower process forces for the ground rake face are demonstrated in the dry cutting process. This might be attributed to a reduced contact area between chip and rake face. However, for wet processes, the process forces of both rake face conditions are nearly on the same

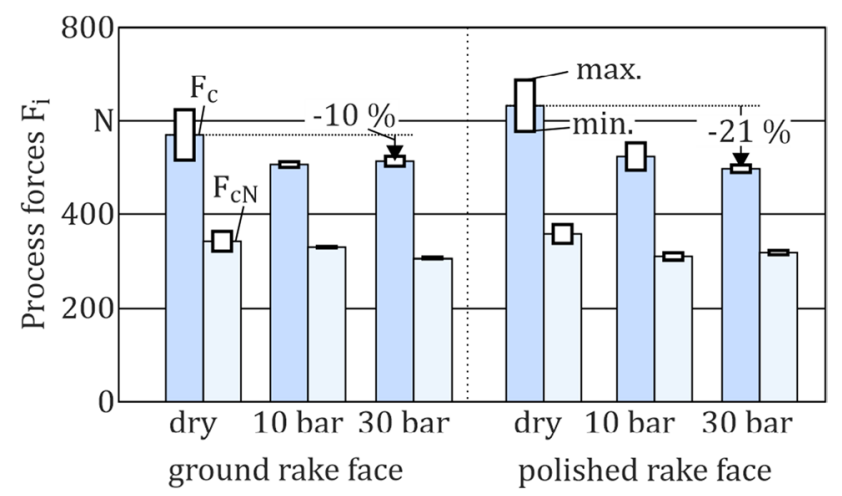

Fig. 9 Measured process forces for the individual processes 
level. Another effect, which influences the process forces, is the cooling effect of the MWF. By using MWF, lower process temperatures and therefore higher process forces due to the higher mechanical strength of the workpiece are expected. Nevertheless, the force measurements show higher process forces for the dry process, which indicates that the reduced contact lengths have a higher influence on the process forces than the thermal softening.

Based on contact lengths and process forces, the average normal loads on the rake face can be calculated with Eq. 5 . In order to exclude the plowing forces from the calculation, the process forces when reaching the minimum chip thickness, $\mathrm{F}_{\mathrm{c}, \mathrm{hmin}}$ and $\mathrm{F}_{\mathrm{cN}, \mathrm{hmin}}$, are subtracted from the cutting and cutting normal forces. The plowing forces are for all processes in similar ranges with $\mathrm{F}_{\mathrm{c}, \mathrm{hmin}}=100-140 \mathrm{~N}$ and $\mathrm{F}_{\mathrm{cN}, \mathrm{hmin}}=160-190 \mathrm{~N}$. $\mathrm{b}$ is the width of cut.

$\sigma_{a v}=\frac{\left(F_{c N}-F_{c N, h \min }\right) \sin \gamma+\left(F_{c}-F_{c, h \min }\right) \cdot \cos \gamma}{b \cdot c l}$

The resulting average normal loads are shown in Fig. 10. Independent of the rake face condition, the lowest average normal loads were calculated for the dry cutting process. Furthermore, the average normal loads increase with increasing MWF pressure. This can be attributed to the reduced contact length. Thus, the forces are acting on a smaller area. Another reason for the higher average normal loads in the wet process is the cooling effect and the reduced thermal softening when using MWF. Distinct differences between ground and polished rake face occur for the wet process with $p=30$ bar. Average normal loads are distinctively higher using the ground rake face in comparison to the polished rake face. One possible explanation is the interaction of the chip with the ground rake face surface. While the chip simply flows over the grinding grooves during the dry process, the chip might be presses into the grooves during the wet machining process due to the higher

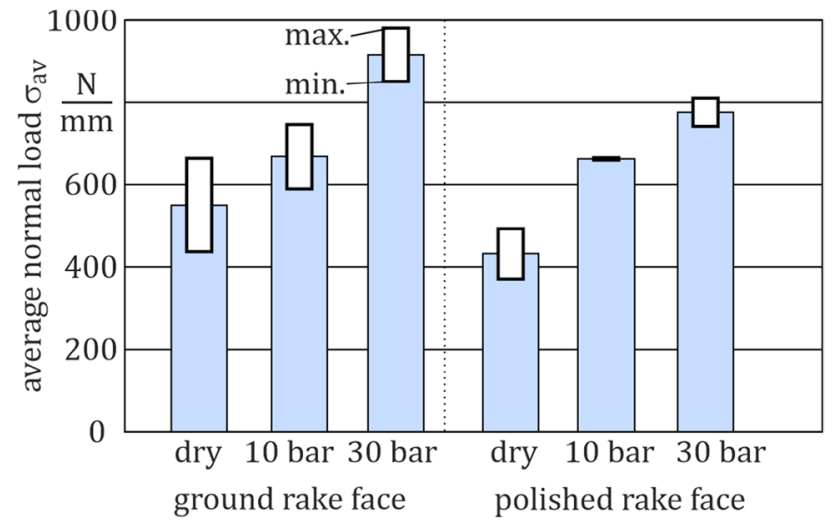

Fig. 10 Average normal loads acting on the rake face normal loads, which leads to a higher resistance against the chip flow. However, more experiments with different rake face conditions and more repetitions are necessary to verify those effects.

\subsection{Average friction coefficient}

The average friction coefficient on the rake face can be calculated as follows [18]:

$\mu=\frac{\left(F_{c N}-F_{c N, h \min }\right)+\left(F_{c}-F_{c, h \min }\right) \cdot \tan \gamma}{\left(F_{c}-F_{c, h \min }\right)-\left(F_{c N}-F_{c N, h \min }\right) \cdot \tan \gamma}$

The results of the calculated friction coefficients are shown in Fig. 11. The friction coefficients are on similar levels between $\mu=0.36$ and $\mu=0.42$ for most processes. A reduced friction coefficient is only calculated for processes with ground rake face and $p=30$ bar. A possible reason for this might be an improved lubrication. A penetration of the MWF in the contact zone might be enabled by the high MWF pressure and the grooves on the rake face. However, existing models in literature by Williams and Tabor [13] and Godlevski et al. [19] expect a better MWF penetration of the ground tool even for the lower pressure $p=10$ bar. In those models, the grinding grooves act as interfacial capillaries, which enable a better penetration. One possible reasons for high friction coefficients of the ground tool with $p=10 \mathrm{bar}$ can be the high cutting speed $\mathrm{v}_{\mathrm{c}},=120 \mathrm{~m} / \mathrm{min}$, which acts against the penetration direction. Furthermore, the models in $[13,19]$ assume a minimum size of the capillaries to enable an efficient penetration. As shown in Fig. 3, the diameter of the grinding grooves is less than $1 \mu \mathrm{m}$, which might be too small when considering the models from literature.

Compared to $p=10 \mathrm{bar}$, a decreased friction coefficient can be achieved for the ground tool and $p=30$ bar. Another explanation approach besides an improved lubrication are the high normal loads acting on the tool with ground rake

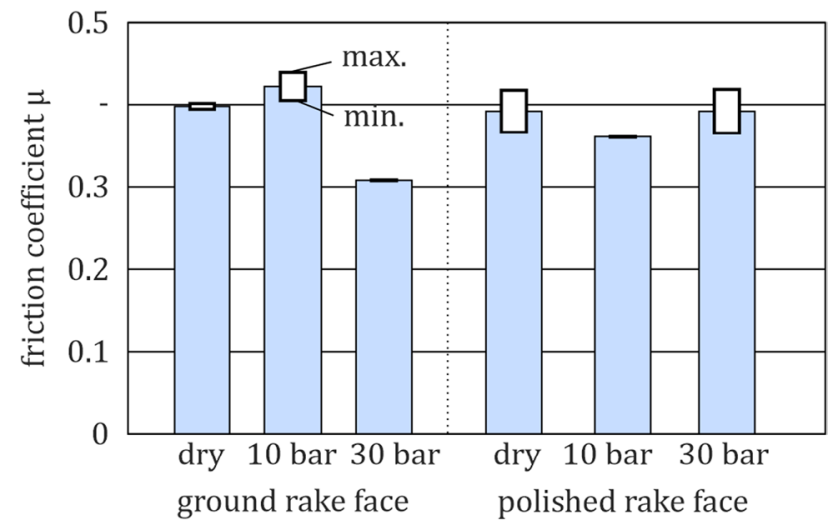

Fig. 11 Calculated friction coefficient for the individual processes 


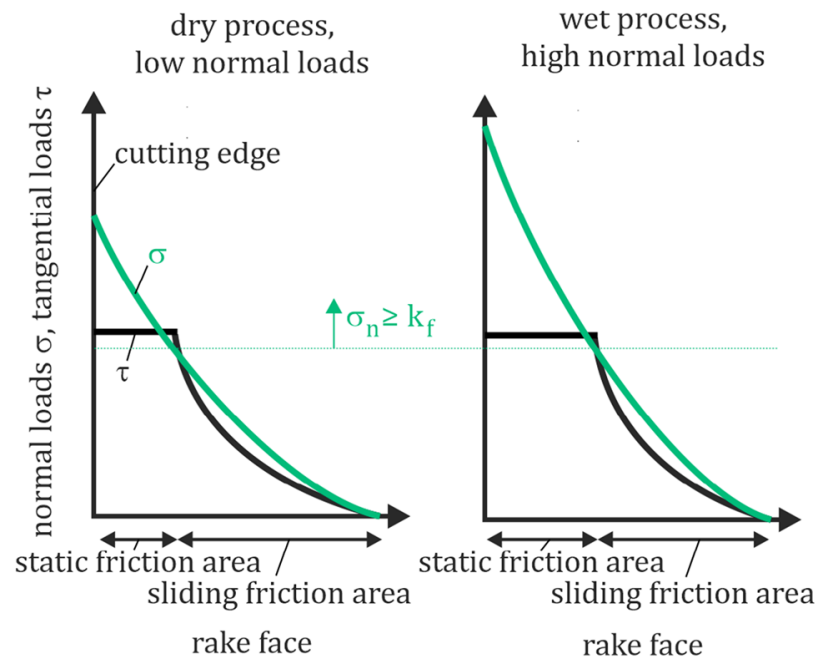

small static friction area, higher ratio of average tangetial to normal loads

greater static friction area, low ratio of average tangetial to normal loads

Fig. 12 Reduced friction coefficients due to increased normal loads $[19,20]$

face when machining with $p=30$ bar. For high normal loads, the tangential loads do not increase proportional to the normal loads. Instead, they are limited by the shear flow stress $\mathrm{k}$ $[20,21]$. This area is called the static friction area (Fig. 12). Due to the high normal loads for processes with $p=30 \mathrm{bar}$ and polished rake face, the static friction area, where the shear flow stress is reached and the tangential load is limited, might increase (Fig. 12, right). Thus, the average friction coefficient $\mu$ decreases.

However, based on the current results, it cannot be concluded whether the reduced average friction coefficient for processes with $p=30$ bar and ground rake face is the result of improved lubrication or an increased static friction area. Therefore, in future investigations, the calculation of local tangential and normal loads on the rake face according to [14] is planned. Based on those results, local friction coefficients can be calculated and more detailed knowledge about the influence of MWF on local friction phenomena can be generated.

\section{Conclusions and outlook}

Based on the investigations, the following conclusions can be drawn:

- The use of MWF significantly influences the chip formation. The contact length strongly decreases when using MWF with higher pressures.
- This can be attributed to the mechanical jet forces of the MWF. Even though they are low compared to the cutting forces, they can lead to a significant deflection of the chip.

- The occurrence of annealing color on the chip was avoided, which indicates lower process temperatures for wet processes.

- Process forces decrease with increasing MWF pressure. This might be the results of the reduced contact lengths.

- The average friction coefficient on the rake face changes only slightly between dry and wet processes.

- The rake face conditions (polished and ground) only show slight influences on contact length, process forces.

- With MWF pressure $p=30$ bar, the ground rake face leads to higher average normal loads and lower average friction coefficients compared to the polished rake face, which might be attributed to changing contact conditions between tool and chip.

In future investigations, it is planned to calculate the local stresses on the rake face based on the measured contact lengths and process forces with the method presented in [14]. Moreover, studies have to be carried out with a wider range of rake face surface conditions to identify the influence of the rake face surface conditions on the lubrication effects. Additionally, investigations with higher cutting speeds $v_{c}$ and higher MWF pressures will be conducted. In addition to taking into account the mechanical loads, the temperatures should also be measured in future investigations. For this purpose, suitable measurement concepts must be set up on the planing test rig.

Acknowledgements The authors appreciate the funding of this work within the Priority Program 2231 "Efficient cooling, lubrication and transportation - coupled mechanical and fluid-dynamical simulation methods for efficient production processes (FLUSIMPRO)" by the German Research Foundation (DFG) - project number 439904924.

Funding Open Access funding enabled and organized by Projekt DEAL.

Availability of data and material Raw data is available on request.

Code availability Not applicable.

\section{Declarations}

Competing interests The authors declare no competing interests.

Open Access This article is licensed under a Creative Commons Attribution 4.0 International License, which permits use, sharing, adaptation, distribution and reproduction in any medium or format, as long as you give appropriate credit to the original author(s) and the source, provide a link to the Creative Commons licence, and indicate if changes were made. The images or other third party material in this article are included in the article's Creative Commons licence, unless indicated 
otherwise in a credit line to the material. If material is not included in the article's Creative Commons licence and your intended use is not permitted by statutory regulation or exceeds the permitted use, you will need to obtain permission directly from the copyright holder. To view a copy of this licence, visit http://creativecommons.org/licenses/by/4.0/.

\section{References}

1. Palanisamy S, McDonald SD, Darguscha MS (2009) Effects of coolant pressure on chip formation while turning Ti6Al4V alloy. Int J Mach Tools Manuf 49(9):739-743

2. Klocke F, Krämer A, Sangermann H, Lung D (2012) Thermomechanical tool load during high performance cutting of hardto-cut materials. Procedia CIRP 1:295-300

3. Ezugwu EO, Bonney J (2004) Effect of high-pressure coolant supply when machining nickel-base, Inconel 718, alloy with coated carbide tools. J Mater Process Technol 153-154:1045-1050

4. Alagan NT, Hoier P, Zeman P, Klement U, Beno T, Wretland A (2019) Effects of high-pressure cooling in the flank and rake faces of WC tool on the tool wear mechanism and process conditions in turning of alloy 718. Wear 434-435

5. Braham-Bouchnak T, Germain G Robert P, Lebrun JL, Auger S (2009) High pressure Qater Het assisted machining of duplex steel: machinability and tool life. Proceedings of the $12^{\text {th }}$ CIRP Conference on Modeling of Machining Operations

6. Klocke F, Döbbeler B, Lakner T (2018) Influence of the coolant nozzle orientation and size on the tool temperature under highpressure coolant supply using an analogy test bench. Production Engineering - Research and Development 12, p. 473-480

7. Claudin C, Mondelin A, Rech J, Fromentin G (2010) Effects of a straight oil on friction at the tool-workmaterial interface in machining. Int J Mach Tools Manuf 50:681-768

8. Cabanettes, F.; Rolland, J.; Dumont, F.; Rech, J.; Dimkovski, Z (2016) Influence of MQL (minimum quantity lubrication) on friction characterizing tool - aluminium alloy contact. J Tribol 138 (2)
9. Sterle L, Pusavec F, Kalin M (2019) Determination of friction in cutting processes: comparison between open and closed tribometers. Procedia CIRP 82:101-106

10. Lakner T, Hardt M (2020) A novel experimental test bench to investigate the effects of cutting fluids on the frictional conditions in metal cutting. Journal of Manufacturing and Material Processing 4 (45)

11. Crafoord R, Kaminski J, Lagerberg S, Ljungkrona O, Wretland A (1999) Chip control in tube turning using a high-pressure water jet. Proc Instit Mech Eng 213:761-767

12 Childs THC (2006) Friction modelling in metal cutting. Wear 260:310-318

13. Williams JA, Tabor D (1977) The role of Lubricants in machining. Wear 43:275-292

14. Bergmann B, Grove T (2018) Basic principles for the design of cutting edge roundings. CIRP Ann Manuf Technol 67:73-78

15. Denkena B, Krödel A, Beblein S (2020) A novel approach to determine the velocity dependency of the friction behavior during machining by means of digital particle image velocimetry (DPIV). CIRP J Manuf Sci Technol 32:81-90

16. Denkena B, Biermann D (2014) Cutting edge geometries. CIRP Ann 63(2):631-653

17. Gomeringer et al. (2018) Mechanical and metal trades handbook. Europa Lehrmittel

18 Merchant ME (1945) Mechanics of the Metal Cutting Process. I. Orthogonal cutting and a type 2 chip. J Appl Phys 16(5):267-275

19. Godlevsky V, Volkov AV, Latyshev VN, Maurin LN: The kinetic of lubrication action during machining. Lubrication Science 9 (2), p. $127-140$

20. Zorev NN: Inter-relationship between shear processes occurring along the tool face and shear plane in metal cutting. International Research in Production Engineering, ASME, New York, 1963, p. 42-49

21. Orowan E (1943) The calculation of roll pressure in hot and cold flat rolling. Proc Inst Mech Eng 150(1):140-167

Publisher's note Springer Nature remains neutral with regard to jurisdictional claims in published maps and institutional affiliations. 